\title{
Fabrication and Evaluation of a Solar Dryer Made From Twin-Wall Clear Polycarbonate Sheets
}

\author{
Daniel Leslie S. $\operatorname{Tan}^{1}$ and Benjamin L. Cinto, $\mathrm{Jr}^{2}$ \\ ${ }^{1}$ PhilRootcrops, Visayas State University \\ ${ }^{2}$ Philippine Higher Education Research Network, Visayas State University
}

\begin{abstract}
This study evaluated the newly designed and fabricated solar dryer based form the following design criteria 1) made of locally available materials, 2) easy to maintain and low maintenance cost, 3) portable, 4) products to be dried should not be exposed to rain and foreign elements (should be clean), and 5) able to dry faster than sundrying method. A solar dryer was fabricated and made mainly of twin-wall polycarbonate sheets with angle bar framing, with 3 layers of removable aluminum screen trays with aluminum framing. It has 3 solar heat collectors that provided additional heat to the drying chambers. Results of the evaluation showed that the maximum average drying temperature attained in the chambers of the solar dryer was $67.6^{\circ} \mathrm{C}$ or an increase of $32.2^{\circ} \mathrm{C}$ from the average highest average outside temperature of $35.4^{\circ} \mathrm{C}$. When the solar heat collectors were removed, the solar dryer was able to attain an average maximum temperature of $57.5^{\circ} \mathrm{C}$ or an increase of $24.5^{\circ} \mathrm{C}$ from an average outside temperature of $33.0^{\circ} \mathrm{C}$. When evaluated to dry fresh saluyot (Corchorus olitorius L) leaves (Initial MC of 89.58\%) and sweetpotato (Ipomoea batatas Lam) tops (Initial MC of 94.50\%), the solar dryer in 2.33 hours reduced the moisture content, wet basis, of the saluyot to an average of $26.54 \%$ as compared to the sundrying method which reduced it to an average of $47.14 \%$ The performance of the dryer will be evaluated further using other available products in the uplands.
\end{abstract}

Keywords: Fabrication, solar dryer, polycarbonate sheets

Correspondence: D.L.S. Tan Address: PhiliRootCrops, Visayas State University, Visca, Baybay City, Leyte Email:dlstan1@yahoo.com DOI: 10.32945/atr36s16.2014 


\section{INTRODUCTION}

Drying is an important component in the preservation of agricultural produce. One of the reasons of the low productivity in the uplands is the absence of postharvest facilities particularly drying facilities to safely store their crops after harvest. Sundrying could help dry the crops but is very dependent to weather conditions. Many crops dried under the sun are of reduced quality because of the exposure to weather and foreign elements. Therefore, a solar dryer was developed to help alleviate the problem of drying crops in the uplands. The objective of the study is to develop a solar dryer based from the following criteria: a) made of locally available materials, b) easy to maintain and low maintenance cost, c) portable, d) products to be dried should not be exposed to rain and foreign elements (should be clean), and e) able to dry faster than sundrying method.

Sun drying is still the most common method used to preserve agricultural products in the country primarily because of economic considerations. Quality of the dried products, however, suffers as the products are exposed to weather elements and other foreign materials. These problems can be solved through the use of a solar dryer which protects the products from foreign and weather elements. Solar dryer usually comprises of collector, a drying chamber and sometimes a chimney (Madhlopa etal., 2002).

Solar dryers are usually classified as direct and indirect solar dryers (Akoy et al., ; Boiln and Salunkhe, 1982). Indirect solar dryers have solar heat collectors that collect heat to the drying chamber, while Direct Solar dryers do not have solar heat collectors but the heat from the sun goes directly to the drying chambers where the products are dried.

As for the drying of medicinal plants, Rocha et al (2011) concluded in their review that the drying process (drying method, velocity and temperature of drying air) has influence on the quality of medicinal plants, that is, the quantity and quality of the active ingredients present in aromatic and medicinal plants are affected by the drying process. In spite of all technical developments, the choice of the correct drying temperature remains a central economic and ecological criterion in the drying of medicinal plants. The values recommended in literature and those used in practice are often far apart, confirming that there is an urgent need for research on this topic. However, drying air temperatures between 50 and $60^{\circ} \mathrm{C}$ appear to be feasible for drying large number of medicinal plants. 
With the many still untapped resources in marginal uplands, the preservation of these products largely depends on the drying process. Sundrying is economical but the quality of the dried products is not guaranteed, hence the appropriate method of drying these products could be by solar drying.

Many solar dryers designs are already available and proven to dry many agricultural produce. There are solar cabinet dryers, solar tunnel dryer, solar tunnel dryers with blowers (Hoheinheim design), and many other designs. However, most of these solar dryers use ordinary or specialized plastic sheets as materials, which may not last very long. A twin-wall polycarbonate plastic sheet material is already available in the market and is growing in popularity as roofing materials for sheds, greenhouses, etc, but has not been used as material for solar dryer. It is a versatile material which is light, strong, and flexible. It can absorb $80-90 \%$ of the sunlight and has UV protection, among other features (Parvin and Williams, 1975; CES Edupack 2010; Serini, 2000). It is also used for solar heating system (Wright, 2010). With these features, a solar dryer could be made fully from the twin-wall polycarbonate sheet.

\section{MATERIALS AND METHODS}

Fabrication of the solar dryer mainly made of twin-wall polycarbonate sheets.

The solar dryer was fabricated at the PhilRootcrops Processing Laboratory and made of twin-wall clear polycarbonate sheets for the roofing and walling of the dryer. The following design criteria were used as guide in the fabrication of the dryer:

i. made of locally available materials, and mainly of twin-wall polycarbonate sheet

ii. easy to maintain and low maintenance cost,

iii. portable,

iv. products to be dried should not be exposed to rain and foreign elements (should be clean), and

v. able to dry faster than sundrying method. 
Evaluation of the performance of the prototype solar dryer

The performance of the fabricated solar dryer was determined both with and without the solar heat collectors. A comparative drying evaluation between the solar dryer and the sundrying method using the Saluyot and Sweetpotato leaves was also conducted.

Infrared imaging of the solar dryer was also taken during the drying operation.

Analysis of data

The data gathered were analyzed and evaluated which included: a) Air temperature of the solar dryer without load, with and without solar heat collector; b) Moisture content of leaves using the solar dryer and sun drying method.

\section{RESULTS AND DISCUSSION}

\section{Description of the Solar Dryer}

Figure 1 shows the exterior or perspective (Figure 1a) and interior (Figure 1b) views of the fabricated solar dryer. It was basically made of very lightweight and clear twin-wall polycarbonate sheet - its roofing, walling and the heat collectors. The framing was made of angle bars. The trays were made of aluminum screen and framing. It has 3 heat collectors and 3 chimneys. Each heat collector is made of black painted GI sheets covered with $4 \times 8 \mathrm{ft}$ twin-wall polycarbonate sheet.

\section{Performance of the Solar Dryer.}

Figure 2 shows that the dryer with the solar heat collectors attached can reach a maximum drying air temperature of $67.6^{\circ} \mathrm{C}$, or a maximum increase of $32.2^{\circ} \mathrm{C}$ from the maximum observed air outside air temperature of $35.4^{\circ} \mathrm{C}$. When evaluated without the solar heat collectors, the dryer was able to reach a maximum temperature of $57.7^{\circ} \mathrm{C}$ as shown in Figure 3. Average temperature attained by the solar dryer with the heat collector was $56.75^{\circ} \mathrm{C}$ with outside average temperature of $33.3^{\circ} \mathrm{C}$, while without the heat collector was $46.4^{\circ} \mathrm{C}$ with outside temperature of $31.7^{\circ} \mathrm{C}$. Naturally, a much higher average temperature was attained with the 
Solar Dryer Made From Twin-Wall Clear Polycarbonate Sheets

presence of the heat collectors. Heat collectors provide additional heat and therefore the additional rise in temperature of the drying chamber. Similar observations were reported by Derbala et al, 2009. Average computations were based from the measurements taken during the day from 9 AM to 5 PM. Higher average temperature could have been attained when the measurements were only up to 4 PM where temperature is considerably much higher than at $5 \mathrm{PM}$ as shown in the Figures 2 and 3. These results show that the heat collector may not be needed when drying products especially dried leaves of medicinal plants which requires $50-60^{\circ} \mathrm{C}$ temperature (Rocha et al, 2011).

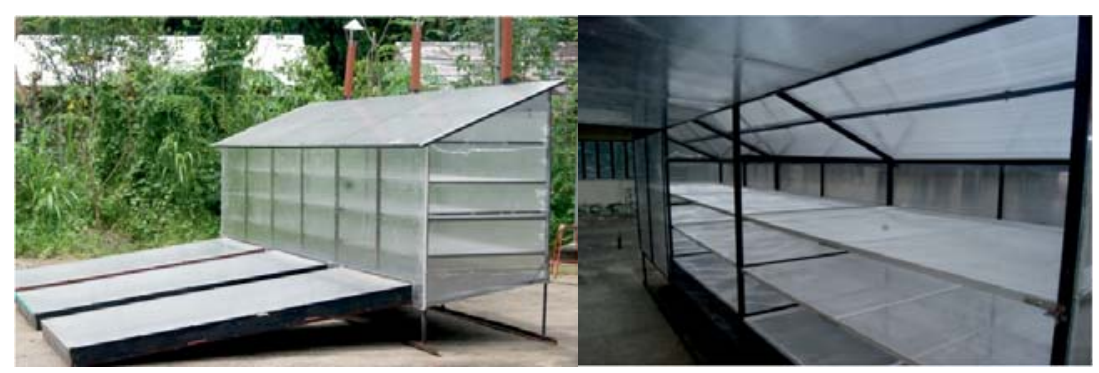

a) Perspective of the solar dryer

b) Interior view of the solar dryer

Figure 1. Views of the fabricated solar dryer made from clear twin-wall polycarbonate sheets.

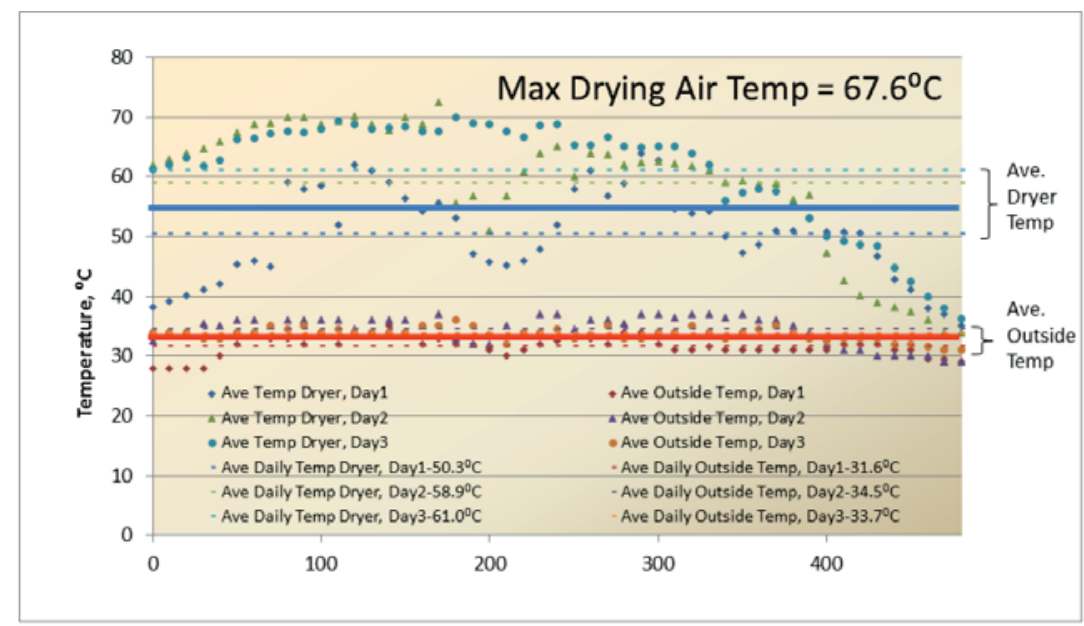

Drying Time, minutes (9:00AM - 5:00PM)

Figure 2. Performance of the fabricated solar dryer with the heat collectors attached. 


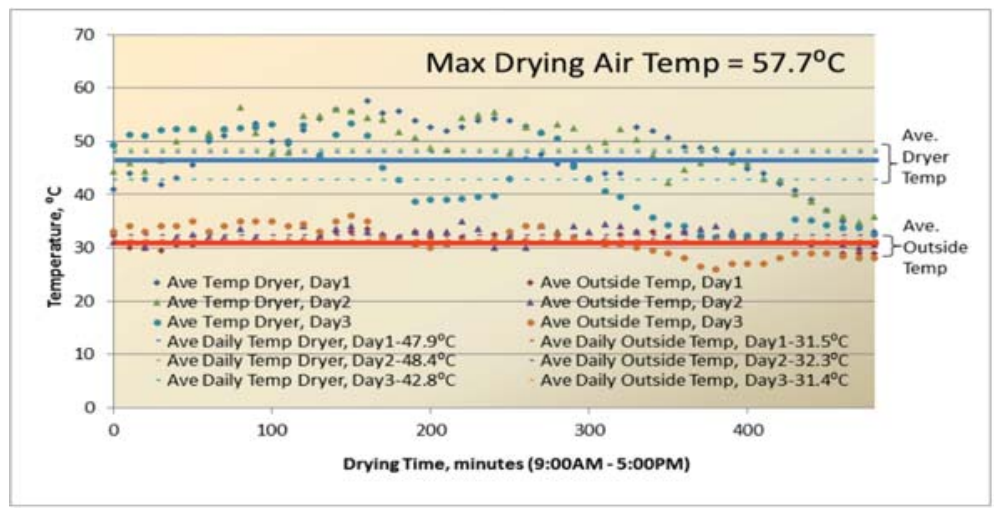

Figure 3. Performance of the fabricated solar dryer without the heat collectors.

Figures 4 and 5 show the linear and polynomial relationship of the drying chamber temperature and the outside air temperature. For the dryer with the heat collectors, the linear relationship shows, at the range of temperature measured, that there is a corresponding increase of 3.85 degree rise for every rise in outside air temperature (from the linear equation: $y=3.855 \mathrm{x}-71.47$, where $\mathrm{y}$ represents the temperature of the drying chamber and $\mathrm{x}$ is the temperature of the outside air). The value of 3.85 is naturally higher than that of the dryer without the heat collector which is only 2.91 (from $y=2.906 x-45.79$, where y represents the temperature of the drying chamber and $\mathrm{x}$ is the temperature of the outside air). Polynomial equations can better describe the relationships between the outside and inside temperatures of the dryer than linear relationships in the range of temperature measured as shown by the $\mathrm{R}^{2}$ values of the equations.

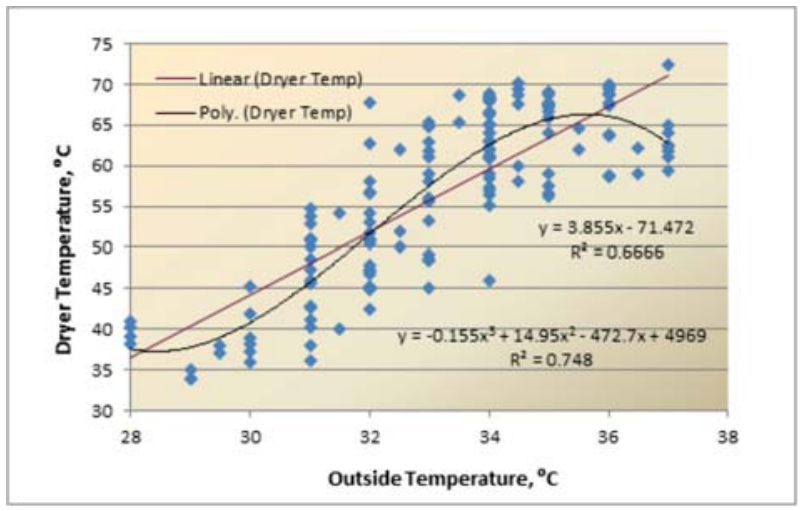

Figure 4. Relationships between the outside air and drying air temperatures of the solar fabricated solar dryer with the solar heat collectors. 


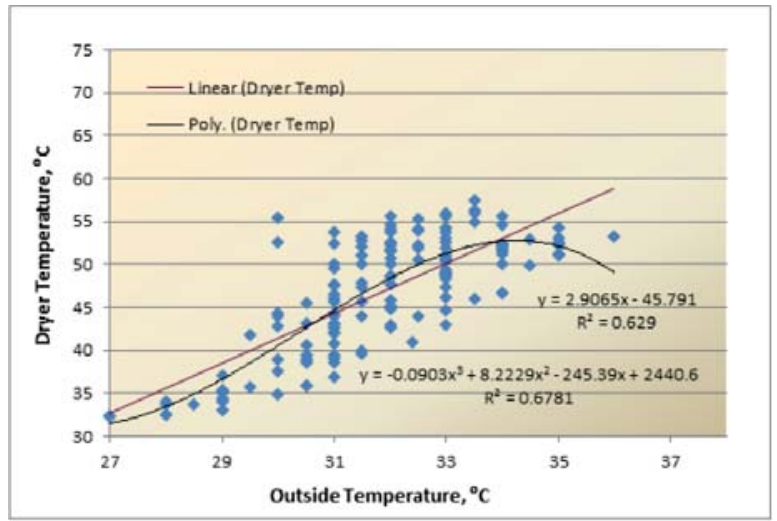

Figure 5. Relationships between the outside air and drying air temperatures of the solar fabricated solar dryer without the solar heat collectors.

Figures 6 and 7 show the temperature distribution of the fabricated solar dryer using an infrared imaging camera as shown from the outside and inside of the dryer with the cassava chippy product being dried. As shown in Figure 5, there is a higher temperature in the solar heat collectors than in the drying chambers, as expected. In the drying chamber, the temperature is quite evenly distributed as shown from the outside. Inside the drying chamber, there is a lower temperature distribution in the lower tray because of the cassava chippy loaded which is still not dried (Figure 7).

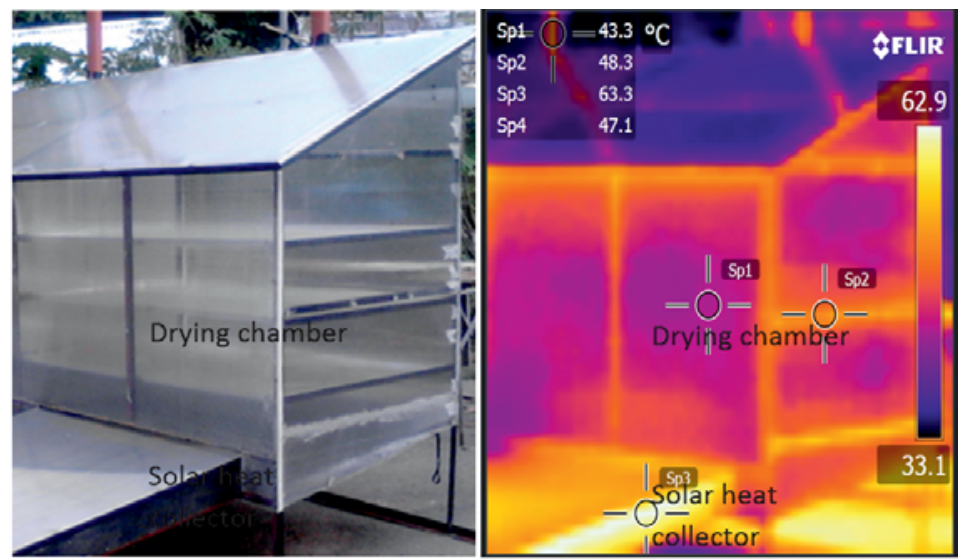

Figure 6. Temperature distribution of the fabricated solar dryer as shown from the outside using an infrared imaging camera with the heat collector. 


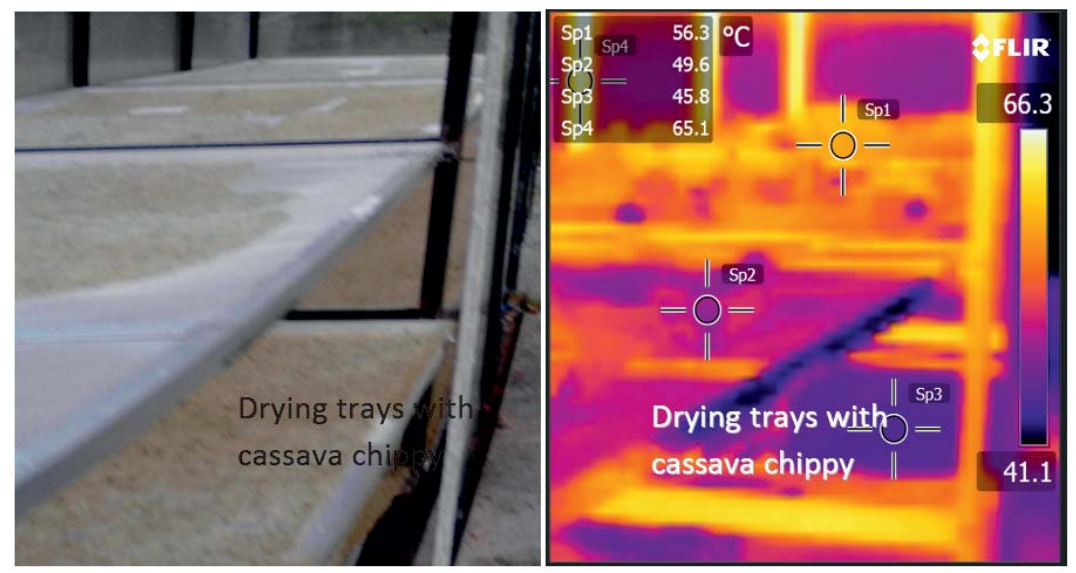

Figure 7. Temperature distribution of the inside of the drying chamber with wet cassava chippy being dried, using an infrared imaging camera with the heat collector.

\section{Drying of Sweetpotato and Saluyot Leaves}

The fabricated solar dryer will be used to dry some of the products available in the uplands like those shown in Figure 8 which will be used for making tea. The dryer was evaluated for drying saluyot and sweetpotato leaves.

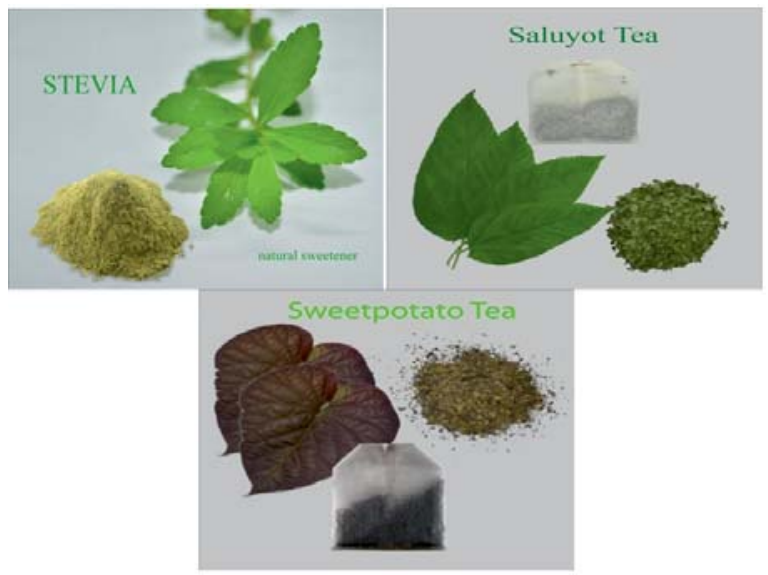

Figure 8. Some of the products that will be dried using the fabricated solar dryer to produce dried leaves for tea and other uses. 
Table 1 shows the moisture content of the the Saluyot and sweetpotato leaves using the dryer and the sundrying method, after drying the leaves for 2 hours and 20 minutes under the sun and using the fabricated solar dryer. The results clearly showed that using the solar dryer can dry the leaves dried faster as shown by the final moisture content of the products. The final moisture content of the Saluyot leaves using the solar dryer was about half of the moisture content of the leaves dried using the sundrying method, while for the sweetpotato leaves, the final moisture content of the leaves using the solar dryer was about a third of the moisture content using the suyndrying method. The results could mainly be attributed to the higher temperature in the drying chamber which is much higher than the outside air temperature as shown in Figure 2.

Table 1. Moisture Content of the Saluyot and Sweetpotato leaves after 2hours \& 20 min of drying by Sundrying Method and by the use of the Solar Dryer with the solar heat collectors.

\begin{tabular}{lccc}
\hline \multicolumn{1}{c}{ Drying Method } & Initial Moisture & \multicolumn{2}{c}{ Final Moisture Content, \% wb } \\
Leaves & Content, \% wb & Solar Drying & Sundrying \\
\hline Saluyot & 89.58 & 26.54 & 47.14 \\
Sweetpotato tops & 84.50 & 28.54 & 71.00 \\
\hline
\end{tabular}

\section{CONCLUSION}

The dryer with the solar heat collectors attained a maximum air temperature of $67.6^{\circ} \mathrm{C}$, without the solar heat collectors, it attained a maximum temperature of $57.5^{\circ} \mathrm{C}$.

With the heat collector, there is a 3.85 rise in the chamber temperature for every rise in outside air temperature, and without the heat collector, 2.91 rise in temperature for every rise in outside air temperature for the outside temperature range measured of $32.2-35.4^{\circ} \mathrm{C}$.

The dryer was able to dry faster than that of sundrying method when used to dry saluyot and sweetpotato leaves.

\section{RECOMMENDATION}

The fabricated solar dryer is recommended for drying agricultural products. A supplemental heat will be explored to provide heat during inclement weather and during the night for continuous drying. 


\section{REFERENCES}

BOILN, H. R., and D.K. SALUNKHE. 1982. Food Dehydration by Solar Energy, CRC Critical Reviews in Food Science and Nutrition, pp:327-354. CES Edupack. 2010. Polycarbonate (PC) specs sheet.

DERBALA, A., N.A.UDROIU, A. MITROI, and C. IACOMI. 2009. Drying of squash using solar tunnel dryer with photovoltaic. Misr J. Ag. Eng., 26(2): $922-934$

EL- AMIN OMDA MOHAMED AKOY, MOHAMED AYOUB ISMAIL, EL-FADIL ADAM AHMED and W. LUECKE Design and Construction of A Solar Dryer for Mango Slices. http://www.researchgate.net/publication /237472327 Retrieved October, 2013

MADHLOPA, A., S.A. JONES, and J.D. KALENGA SAKA. 2002. A solar air heater with compositeabsorber systems for food dehydration. Renewable energy, 27:27-37.

PARVIN, M and J.G. WILLIAMS. 1975. The effect of temperature on the fracture of polycarbonate.Journal of Materials Science 10 (11): 1883.

ROCHA, R.P., E.C. MELO, and L.L. RADÜNZ. 2011. Influence of drying process on the quality of medicinal plants: A review. Journal medicinal plants research 5(33): 7076-7084."

SERINI, V. 2000. "Polycarbonates" in Ullmann's Encyclopedia of Industrial Chemistry, Wiley-VCH, Weinheim Wright, Alan Derek, 2010. Solar heating system EP 2499434 A2 